\section{Abstractions}

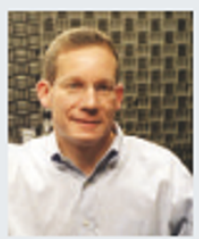

MAKING THE PAPER

Horacio Frydman

\section{Bacteria exploit stem cells and their surroundings in order to reproduce.}

As a grad student, Horacio Frydman was studying sterile fruitflies when something unusual caught his eye. "One of the mutant lines had a strange pattern of staining in the part of the ovary close to the egg cells," he recalls. "Almost everybody thought it was an artefact. But after taking a closer look with an electron microscope, he concluded that the staining was caused by infectious bacteria - more precisely, Wolbachia.

Wolbachia is extremely adept at infecting all types of insects. It also invades small parasitic worms, such as the filarial nematodes that cause river blindness and elephantiasis in places such as Frydman's home country, Brazil.

The bacterium typically inhabits cells in the testes and ovaries of its host, and is passed on from generation to generation through the mother. But until recently, no one knew which cellular mechanisms Wolbachia exploits to infect its host and spread so successfully down the generations

'I saw Wolbachia as an opportunity to combine my interest in fruitfly development with studying host-parasite interactions in tropical diseases," says Frydman.

So after completing his $\mathrm{PhD}$ work in the lab of stem-cell researcher Allan Spradling, at the Carnegie Institution of Washington, Frydman wrote a proposal for examining the transmission of Wolbachia in fruitflies (Drosophila). He then looked for a lab that would take him. "That put me in the unusual position of having a project without having an actual job," he says.

Eventually, he found a home in the laboratory of Nobel laureate Eric Wieschaus at Princeton University in New Jersey. "Although Eric had never previously worked with Wolbachia, he generously allowed me to bring my own project to his very successful lab," enthuses Frydman.

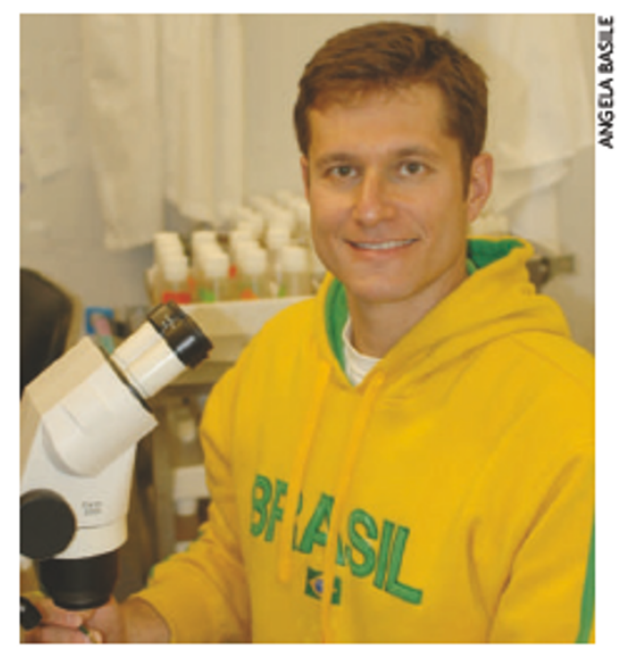

His first step was to improve the reagents and methods used to visualize Wolbachia in living and fixed tissues. Armed with the right tools, Frydman found that the bacteria clustered in two places in the germarium, a part of the fly's ovary where the development of eggs begins.

Having trained in Spradling's lab, Frydman quickly realized that the clusters were in a region known to include two or three of the somatic stem cells that generate structures to protect the embryo during development. But the Wolbachia was not inside the stem cells themselves. Instead, as reported on page 509 of this issue, the bacteria were found in the surrounding 'niche', a microenvironment that provides stem cells with the factors needed for their specialized properties.

"This positioning probably facilitates Wolbachia transmission and may have a role in the success of the parasite," says Frydman. Indeed, it is possible that by homing in on the niche the bacteria are able, like stem cells, to renew and amplify themselves, and then infect many eggs.

Frydman now plans to explore what Wolbachia can teach us about the stem-cell niche itself. "We are only just learning about the niche, but the bacteria have been recognizing and living in it for millions of years."
So, which is better?

It's not a question of proving something is better. We want to define the limits of nanowires, push them as far as wecan and find real applications. There's room for many different types of nanostructures in the future. As long as people focus honestly on the science, things will progress naturally - although I do feel some are too narrowly focused on nanotubes.

How does your paper strengthen the argument in favour of nanowires?

Our work is state-of-the-art. We cannot yet judge whether nanowires will become the next microelectronics technology, because so many other issues need to be resolved - such as manufacturing and economics. But we have shown that nanowires are aviable alternative to silicon chips and nanotubes. Now we're focusing on the next big questions.

\title{
QUANTIFIED NEW ZEALAND
}

\section{A numerical per spective on Nature authors.}

At the Institute of Geological and Nuclear Sciences in New Zealand, Cornel de Ronde leads the offshore minerals programme, conducting research on submarine volcanoes. De Ronde spends three to four weeks at sea each year, surveying volcanoes and collecting samples.

Survey work is tough, he says. He does 12-hour shifts, often at night in pitching, rolling seas, with lots of noise and little privacy. But itcan bevery rewarding. The field is still in its infancy and, as such, offers its participants the opportunity to witness things never seen before. A striking example is the discovery of an erupting submarine volcano, witnessed by de Ronde and his colleagues during the 2004 Ring of Fire expedition to the Mariana arc, and detailed in their paper in Nature this week (see page 494).
US\$ $\$ 600,000$ isspentannually

by de Ronde's volcano research project.

17 authors from the United States, Canada, New Zealand and Japan contributed to the paper describing submarine volcanic activity published in Nature this week.

15 submissions to Nature this year have come from New Zealand ( $<1 \%$ of all submissions).

42 days is the longest de Ronde has spent surveying volcanoes atsea. 